\title{
Evaluation of our first-year endoscopic retrograde cholangiopancreatography results
}

\author{
- Ufuk Arslan, ๑ Hacı Murat Çaycı, @ Ali Tardu, ๑ Umut Eren Erdoğdu \\ Department of General Surgery, Health Sciences University, Bursa Yüksek Ihtisas Training and Research Hospital, Bursa, Turkey
}

\begin{abstract}
Introduction: In this study, the results of the first year of endoscopic retrograde cholangiopancreatography (ERCP), which has been started to be performed in our center, have been evaluated.

Materials and Methods: A retrospective analysis was carried out with data of 345 patients who underwent ERCP performed by the same team at a single center between April 2019 and April 2020. The patients were assessed for demographic data, indications for the procedure, procedure-related complications, endoscopic findings and interventions.

Results: A total of 345 patients underwent the procedure, with a total of 412 procedures were performed. The patient group comprised 210 women and 135 men, with a mean age of 56.4 (19-86) years. The mean duration of the procedure was $12(4-48)$ minutes. The most common $(60.4 \%)$ indications for ERCP were radiologically detected ductus choledochus stones and elevated liver enzymes and/or hyperbilirubinemia. Successful cannulation was performed using a standard sphincterotome in a total of 370 procedures. The number of procedures performed using a precut needle-knife sphincterotome was 28; however, cannulation was successful only in 16 . The total cannulation rate was $93.6 \%$. The most common complication (2.9\%) was post-ERCP pancreatitis and 30 (7.2\%) patients developed post-ERCP complications.

Conclusion: Endoscopic retrograde cholangiopancreatography is an endoscopic method commonly used for the treatment of pancreaticobiliary diseases. We believe that it should be applied as a therapeutic procedure rather than as a diagnostic tool, being an invasive procedure.

Keywords: Ductus choledochus stones; endoscopic retrograde cholangiopancreatography (ERCP); pancreaticobiliary system; pancreatitis; perforation.
\end{abstract}

\section{Introduction}

Endoscopic retrograde cholangiopancreatography (ERCP) is a commonly used technique for the diagnosis and treatment of benign and malignant pancreaticobiliary diseases. It was first performed by McCune in 1968 for diagnostic purposes, while Kawai performed the first sphincterotomy in 1974. Since then, ERCP has continuously evolved as a diagnostic and therapeutic tool. ${ }^{[1,2]}$ Although used initially for diagnosis, it is today used rather as a therapeutic procedure upon the development of such diagnostic methods as magnetic resonance cholagiopancreatography (MRCP) and endoscopic ultrasound (EUS). ${ }^{[3]}$ 
ERCP is most frequently needed for ductus choledochus stones and the most common complication of the procedure is post-ERCP pancreatitis. ${ }^{[3]}$ Post-endoscopic sphincterotomy (EST) stone extraction is successful in more than $90 \%$ of cases, while large and impacted stones can be broken up by lithotripsy and removed using a balloon-basket catheter ${ }^{[4]}$ Stents can be used for malignant or benign biliary strictures and postoperative biliary leaks. A biopsy can be used for the masses located in the pancreaticobiliary tract and ampulla. ${ }^{[4]}$

In this study, the first year results of ERCP, which has started to be made in our center, are evaluated.

\section{Materials and Methods}

In this study recorded and retrospectively analyzed the data of 345 patients who underwent ERCP in the endoscopy unit of the Bursa Higher Specialization Training and Research Hospital between April 2019 and April 2020. The demographic data, duration of procedure, indications for the procedure, procedure-related complications and therapeutic procedures performed were accessed from the records. All procedures were performed by the same endoscopy team. The study included patients above the age of 18 years who were indicated for ERCP. All patients submitted written informed consent before the procedure.

A Fujifilm ED-580XT® videoduodenoscope was used for the procedures. Prior to the procedure, all patients were consulted for anesthesia and were administered outpatient anesthesia at doses suitable for their comorbidities. Procedures were performed following eight hours of fasting. For patients using anticoagulants, the medication was discontinued seven days prior to the procedure, and low-molecular-weight heparin was administered when considered necessary. All procedures were performed in the standard prone position. The heart rate and oxygen saturation of each patient was monitored. During the procedure, patients were administered 2-4 1/min oxygen and $10 \%$ oral topical lidocaine for throat anesthesia. When the papilla cannulation was challenging due to intestinal peristalsis, the patients were administered hyoscine $\mathrm{N}-$ butyl bromide during the procedure. Urografin ${ }^{\circledR}$ diluted 1:3 with normal saline was used as the contrast agent. Following the procedure, patients were kept under observation for one hour. Patients with no complaints were discharged. The patients were invited for a follow-up visit the next day when the physical examination was repeated and biochemical tests were requested.

\section{Results}

Analyzed in the study were 412 ERCPs carried out on 345 patients. The patient group comprised 210 women and 135 men with an mean age of 56.4 (19-86) years, in which the mean operation duration was 12 (4-48) minutes. The most common indications were radiologically detected ductus choledochus stones and elevated liver enzymes and/or hyperbilirubinemia (60.4\%). Other indications included biliary pancreatitis, malignancy, cholangitis, biliary fistula, biliary tract parasites and stent removal (Table 1).

A duct of Wirsung cannulation was performed in 82 (19.9\%) procedures during ductus choledochus cannulation. Of these patients, 71 (17.2\%) had post-ERCP elevated serum amylase levels, 12 (2.9\%) had been hospitalized upon a diagnosis of pancreatitis; and two (0.48\%) developed postoperative perforations. A duodenal perforation occurring in one patient and ductus choledochus perforation in another patient were treated surgically, and both were discharged without event. Of the eight patients who experienced post-ERCP bleeding, bleeding control was achieved through re-ERCP in two, while six patients were treated through conservative methods.

Of the six (1.45\%) patients who developed post-ERCP cholangitis, one was a 54-year-old male, who had known chronic obstructive pulmonary disease and who smoked, who developed abdominal pain, fever and tachycardia after the procedure. A contrast-enhanced abdominal computed tomography (CT) was performed on the patient. There was no radiological perforation sign, the oral intake of the patient was discontinued and conservative treatment was administered. The patient was observed with

\section{Table 1. ERCP indications}

\begin{tabular}{lcc} 
Indication & $\mathbf{n}$ & $\mathbf{\%}$ \\
\hline Choledochal stone & 153 & 37.1 \\
Elevated liver enzymes & 96 & 23.3 \\
hyperbilirubinemia & & \\
Pancreatitis & 38 & 9.2 \\
Periampullary tumor & 29 & 7 \\
Bile duct tumor & 14 & 3.4 \\
Cholangitis & 20 & 4.8 \\
Biliary fistula & 12 & 2.9 \\
Hydatid cyst & 4 & 0.97 \\
Stent removal & 46 & 11.1 \\
\end{tabular}


clinical progression and elevated cholestasis enzymes one day later, and underwent re-ERCP. A cholangiography revealed a residual stone and mud in the common hepatic bile duct. Biliary stenting was performed on the patient, whose treatment continued in the intensive care unit. The patient developed sepsis signs, despite the biliary stenting, and was mechanically ventilated due to progressive renal dysfunction and respiratory stress. He died two days after the procedure. Another patient was surgically treated due to basket catheter impaction around the stone within the ductus choledochus. An esophageal laceration noted in one patient was treated through endoscopic metal stenting (Table 2).

A total of 370 successful cannulations were performed using a standard sphincterotome. While 28 procedures were performed using a precut needle-knife sphincterotome, cannulation was successful only in 16 . The total cannulation rate was $93.6 \%$ (Table 3). The number of failed cannulations was 26 , which were due to abnormal papilla localization, previous gastrointestinal tract surgery, papilla obstruction and patient intolerance (Table 4). Aside from this, 182 stone extractions with balloon-basket catheters, 73 biliary stentings, 46 stent removals, three pancreatic stentings, six mechanical lithotripsies, 15 biopsies and 13 biliary dilatation procedures were performed (Table 3 ) (Figs. 1a, b, 2a, b).

\section{Table 2. ERCP complications}

\begin{tabular}{lcc} 
Complication & $\mathbf{n}$ & $\%$ \\
\hline Elevated serum amylase level & 71 & 17.2 \\
$\quad$ Less than twice & 38 & 9.2 \\
$\quad$ More than twice & 21 & 5.1 \\
$\quad$ Pancreatitis requiring & 12 & 2.9 \\
$\quad$ hospitalization & & \\
Wirsung cannulation & 82 & 19.9 \\
Perforation & & \\
$\quad$ Requiring surgery & 2 & 0.48 \\
$\quad$ Not requiring surgery & 0 & \\
Bleeding & & \\
$\quad$ Endoscopic treatment & 2 & 0.48 \\
$\quad$ Conservative treatment & 6 & 1.45 \\
Cholangitis & 6 & 1.45 \\
Basket impaction & 1 & 0.24 \\
Esophageal laceration & 1 & 0.24 \\
Mortality (cholangitis) & 1 & 0.24 \\
\end{tabular}

\section{Discussion}

Used to diagnose and treat pancreaticobiliary diseases, ERCP is a combined fluoroscopic and endoscopic procedure involving accessing a second part of the duodenum with a side-viewing endoscope. ${ }^{[3]}$ The most common indications include obstructive jaundice, biliary or pancreatic ductal diseases, pancreatitis, biliary obstruction or fistula, periampullary malignancies and parasitic diseases of the biliary tract. ${ }^{[3]}$ The procedure can be performed for either diagnostic or therapeutic purposes. It is less commonly used as a diagnostic tool, and only for imaging, biopsy and brush cytology in selected patients. ${ }^{[3]}$ It is used as a therapeutic tool for EST, stenting, stone extraction and biliary dilatation. ${ }^{[5-7]}$ In the present study, the most common indications for ERCP were ductus choledochus

\section{Table 3. Therapeutic procedures performed}

\begin{tabular}{lcc} 
Procedure & $\mathbf{n}$ & $\%$ \\
\hline Successful cannulation & 386 & 93.6 \\
Sphincterotomy & 322 & 78.1 \\
Balloon basket retrieval of stone & 182 & 44.1 \\
Biliary stenting & 73 & 17.7 \\
$\quad$ Plastic stent & 69 & 16.7 \\
$\quad$ Metal stent & 4 & 0.98 \\
Stent removal & 46 & 11.1 \\
Pancreatic stenting & 3 & 0.7 \\
Mechanical lithotripsy & 6 & 1.4 \\
Biopsy & 15 & 3.6 \\
$\quad$ Malignant & 7 & 1.7 \\
$\quad$ Benign & 8 & 1.9 \\
Biliary dilatation & 13 & 3.1 \\
Pre-cut & 28 & 6.8 \\
$\quad$ Successful & 16 & 3.9 \\
Failed & 12 & 2.9 \\
\hline
\end{tabular}

\section{Table 4. Causes of failed cannulation}

\begin{tabular}{lcc} 
Cause & $\mathbf{n}$ & $\%$ \\
\hline $\begin{array}{l}\text { Abnormal papilla localization } \\
\begin{array}{l}\text { Previous gastrointestinal } \\
\text { system surgery }\end{array}\end{array}$ & 10 & 2.4 \\
$\begin{array}{l}\text { Complete/incomplete } \\
\text { obstruction of the papilla }\end{array}$ & 9 & 2.2 \\
$\begin{array}{l}\text { Patient intolerance or } \\
\text { insufficient premedication }\end{array}$ & 3 & 0.7 \\
\end{tabular}



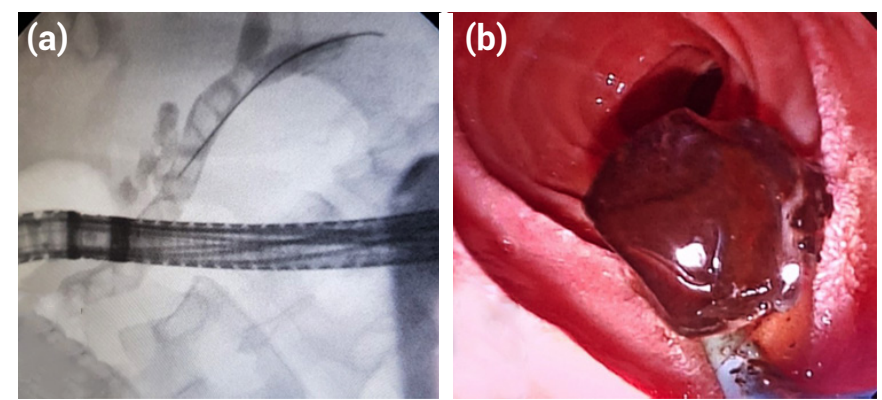

Figure $1(\mathbf{a}, \mathbf{b})$. Cholangiography and endoscopic image of a choledochal stone.
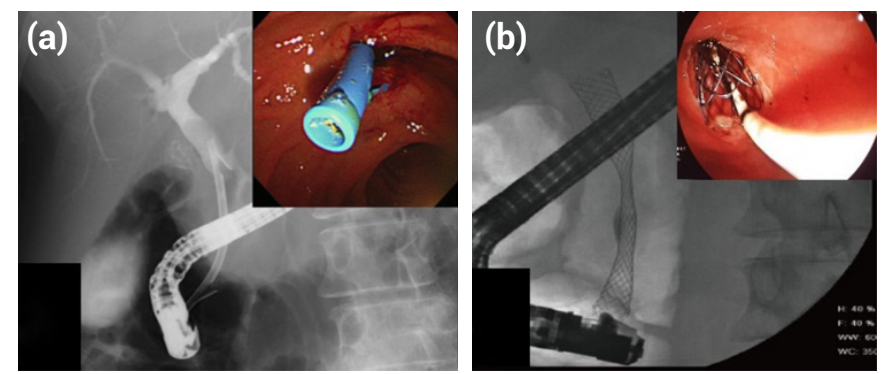

Figure 2 (a, b). Cholangiography and endoscopic image of biliary stenting.

stones (37.1\%), pancreaticobiliary malignancies (10.4\%) and biliary pancreatitis $(9.2 \%)$.

Endoscopic retrograde cholangiopancreatography is generally considered to be an effective and reliable procedure, although complications may occur attributable to several reasons, such as the patient's anatomical differences, disease-related factors (periampullary tumors, papillabased stones) and the experience of the endoscopist. ${ }^{[8]}$ A previous study reported an overall complication rate of $7.9 \%$ after ERCP, while another study evaluating 4.561 cases reported this rate to be $5 \% \cdot{ }^{[9,10]}$ In the present study, the overall complication rate was $7.5 \%$, which is consistent with the literature.

The most common post-ERCP complication was pancreatitis (3.47\%). The associated mortality was reported to be $3.08 \%$, although the incidence may increase to $15 \%$ in high-risk patients. ${ }^{[11,12]}$ In the present series, the rate of pancreatic ductal cannulation was $19.9 \%$ and the postERCP elevated serum amylase level was $17.2 \%$. Of the total, 12 patients developed pancreatitis, of which nine received conservative treatment and three underwent endoscopic pancreatic stenting.

The incidence of post-ERCP bleeding was $2 \% \cdot{ }^{[13]}$ The direction recommended for a standard EST is the 11-1 o'clock position. Bleeding is often associated with ESTs performed in the wrong direction, difficult cannulation and prolonged operation. ${ }^{[13]}$ It can occur up to two weeks after the procedure and is associated with a $3.54 \%$ mortality rate. ${ }^{[14]}$ The risk factors for post-ERCP bleeding include coagulopathy, the use of anticoagulants within the first three days of sphincterotomy, pre-ERCP cholangitis, bleeding during the initial ERCP and a low-volume center. ${ }^{[15]}$ Treatment methods are classified as either non-invasive or invasive. The non-invasive treatment methods include hemodynamic stabilization, increasing the platelet count to above 50.000 in the presence of coagulopathy, decreasing the International Normalized Ratio (INR) to below 1.5, plasma and blood transfusion and discontinuation, and anticoagulant therapy. ${ }^{[16]}$ Invasive treatment methods, in turn, include adrenaline injection, sclerotherapy, electrocauterization and clip placement. ${ }^{\left[{ }^{[7]}\right.}$ In the present series, a total of eight patients encountered bleeding, two of whom underwent an endoscopic intervention. Bleeding was controlled through adrenaline injections and electrocauterization.

The incidence of ERCP-related perforations is below 1\%. ${ }^{[8]}$ Patients with microperforations in the periampullary region and bile duct often make a full recovery through conservative treatment. Post-perforation intraabdominal collections, however, may require percutaneous drainage. Biliary stenting can be used if the perforation is in the bile duct. Luminal perforations detected during the procedure must be closed with endoscopic clips. ${ }^{[18]}$ Surgery should be performed on patients who are unresponsive to conservative treatment, and who have intraabdominal free air and fluid collections. In the present series, two $(0.48 \%)$ patients experienced postoperative perforations, one of which was a patient with a periampullary tumor. A preoperative biliary stenting was performed due to hyperbilirubinemia. The patient had no postoperative symptoms, and was scheduled for elective surgery two days later. The proximal end of the stent was observed to cause a ductus choledochus perforation preoperatively and incidentally. A standard Whipple procedure was performed on the patient. The second patient with a perforation had a ductus choledochus stone. In ERCP, a duodenal perforation occurred during EST. The patient, who experienced postoperative intraabdominal pain, underwent CT imaging and was diagnosed with a perforation. Conservative treatment was administered, oral intake was discontinued and wide-spectrum antibiotherapy was initiated. Progression was noted in the patient's physical examination findings and biochemical parameters despite the conservative treatment, and a laparotomy was performed three days later. Primary repairs of the duodenum and omentopexy were made. No mortality was observed in 
the two patients with perforations.

The rate of post-ERCP cholangitis is $1.4 \%$ and the mortality rate can increase to $7.85 \%$ in the presence of post-ERCP cholangitis. ${ }^{[19]}$ This can be attributed to the failure of the contrast agent and bile to pass through the duodenum, stent-associated infections and insufficiently disinfected tools. ${ }^{[20]}$ In the present series, six (1.45\%) patients developed post-ERCP cholangitis, one of which died from multiorgan failure, despite biliary stenting.

Several studies have reported a rate of ductus choledochus cannulation of over $90 \%$. In the present study, the rate of successful cannulation was $93.6 \%$. Using a guide wire for cannulation increases the success of the procedure, and also reduces the risk of post-ERCP pancreatitis. ${ }^{[2]}$ Our clinic also uses the selective cannulation technique using a guide wire. When such a cannulation cannot be achieved, a pre-cut technique with a needleknife sphincterotome is performed. In the present study, such a pre-cut technique was used in 28 procedures, and cannulation was successful in 16 patients. Cannulation was unsuccessful in a total of 26 patients, with the most common cause being papilla within the diverticulum, previous gastric surgery and stenotic papilla.

\section{Conclusion}

Endoscopic retrograde cholangiopancreatography can be used in the process of treatment instead of diagnosis for pancreaticobiliary diseases due to its invasive nature. The success of ERCP is dependent upon the disease characteristics as well as the experience of the endoscopist.

\section{Disclosures}

Ethichs Committee Approval: Retrospective study.

Peer-review: Externally peer-reviewed.

Conflict of Interest: None declared.

Authorship Contributions: Concept - A.T.; Design U.A., U.E.E.; Supervision - H.M.C.; Materials - A.T.; Data collection and/or processing - U.A., U.E.E.; Analysis and/ or interpretation - U.E.E.; Literature search - H.M.C.; Writing - U.A., A.T.; Critical review - H.M.C.

\section{References}

1. McCune WS, Shorb PE, Moscovitz H. Endoscopic cannulation of the ampulla of vater: a preliminary report. Ann Surg 1968;167:752-6. [CrossRef]

2. Kawai K, Akasaka Y, Murakami K, Tada M, Koli Y. Endoscopic sphincterotomy of the ampulla of vater. Gastrointest Endosc 1974;20:148-51. [CrossRef]

3. Meseeha M, Attia M. Endoscopic retrograde cholangiopancreatography (ERCP). StatPearls [Internet]. Treasure Island (FL): StatPearls Publishing (2020)

4. Acar F, Şahin M, Yılmaz H, Alptekin H, Kafalı ME, Ece İ. Endoskopik retrograt kolanjiopankreatikografi deneyimlerimiz. Selcuk Med J 2014;30:111-4.

5. Kim JY, Lee HS, Chung MJ, Park JY, Park SW, Song SY, et al. Bleeding complications and clinical safety of Endoscopic retrograde cholangiopancreatography in patients with liver cirrhosis. Yonsei Med J 2019;60:440-5. [CrossRef]

6. ASGE Standards of Practice Committee, Buxbaum JL, Abbas Fehmi SM, Sultan S, Fishman DS, Qumseya BJ, et al. ASGE guideline on the role of endoscopy in the evaluation and management of choledocholithiasis. Gastrointest Endosc 2019;89:1075-105.e15. [CrossRef]

7. Dahale AS, Puri AS, Sachdeva S, Srivastava S, Kumar A. Endoscopic Retrograde Cholangiopancreaticography in Children: A Single-center Experience From Northern India. Indian Pediatr 2019;56:196-8. [CrossRef]

8. Szary NM, Al-Kawas FH. Complications of endoscopic retrograde cholangiopancreatography: how to avoid and manage them. Gastroenterol Hepatol (N Y) 2013;9:496-504.

9. Wang P, Li ZS, Liu F, Ren X, Lu NH, Fan ZN, et al. Risk factors for ERCP-related complications: a prospective multicenter study. Am J Gastroenterol 2009;104:31-40. [CrossRef]

10. Williams EJ, Taylor S, Fairclough P, Hamlyn A, Logan RF, Martin D, et al. Risk factors for complication following ERCP; results of a large-scale, prospective multicenter study. Endoscopy 2007;39:793-801. [CrossRef]

11. Andriulli A, Loperfido S, Napolitano G, Niro G, Valvano MR, Spirito $F$, et al. Incidence rates of post-ERCP complications: a systematic survey of prospective studies. Am J Gastroenterol 2007;102:1781-8. [CrossRef]

12. Wang AY, Strand DS, Shami VM. Prevention of post-endoscopic retrograde cholangiopancreatography pancreatitis: medications and techniques. Clin Gastroenterol Hepatol 2016;14:1521-32. [CrossRef]

13. Prachayakul V, Aswakul P. Endoscopic retrograde cholangiopancreatography-related perforation: management and prevention. World J Clin Cases 2014;2:522-27. [CrossRef]

14. Ferreira LE, Baron TH. Post-sphincterotomy bleeding: who, what, when, and how. Am J Gastroenterol 2007;102:2850-8.

15. Freeman ML. Adverse outcomes of ERCP. Gastrointest Endosc 2002;56:273-82. [CrossRef]

16. Veitch AM, Vanbiervliet G, Gershlick AH, Boustiere $C$, Baglin TP, Smith LA, et al. Endoscopy in patients on antiplatelet or anticoagulant therapy, including direct oral anticoagulants: British Society of Gastroenterology (BSG) and European Society of Gastrointestinal Endoscopy (ESGE) guidelines. Gut 2016;65:374-89. [CrossRef]

17. Mirjalili SA, Stringer MD. The arterial supply of the major duodenal papilla and its relevance to endoscopic sphincterotomy. Endoscopy 2011;43:307-11. [CrossRef] 
18. Kwon $\mathrm{Cl}$, Song $\mathrm{SH}, \mathrm{Hahm} \mathrm{KB}, \mathrm{Ko} \mathrm{KH}$. Unusual complications related to Endoscopic retrograde cholangiopancreatography and its endoscopic treatment. Clin Endosc 2013;46:251-9.

19. Kola A, Piening B, Pape UF, Veltzke-Schlieker W, Kaase M, Geffers $C$, et al. An outbreak of carbapenem-resistant OXA48 - producing Klebsiella pneumonia associated to duodenoscopy. Antimicrob Resist Infect Control 2015;4:8.
20. Wendorf KA, Kay M, Baliga C, Weissman SJ, Gluck M, Verma $\mathrm{P}$, et al. Endoscopic retrograde cholangiopancreatographyassociated AmpC Escherichia coli outbreak. Infect Control Hosp Epidemiol 2015;36:634-42. [CrossRef]

21. Cotton PB. Are low-volume ERCPists a problem in the United States? A plea to examine and improve ERCP practice-NOW. Gastrointest Endosc 2011;74:161-6. [CrossRef] 